\title{
Differential prevalence and demographic and clinical correlates of antidepressant use in American bipolar I versus bipolar II disorder patients
}

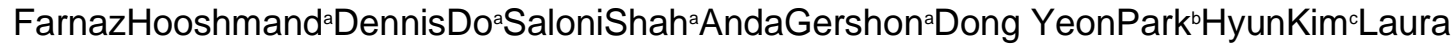
D.YuenaBernardoDell'Osso adPo W.Wang ${ }^{a}$ Terence A.KetteraShefaliMillera

\section{Abstract}

Aims

Antidepressant use is controversial in bipolar disorder (BD) due to questionable efficacy/psychiatric tolerability. We assessed demographic/clinical characteristics of baseline antidepressant use in BD patients.

Methods

Prevalence and correlates of baseline antidepressant use in 503 BD I and BD II outpatients referred to the Stanford Bipolar Clinic during 2000-2011 were assessed with the Systematic Treatment Enhancement Program for BD (STEP-BD) Affective Disorders Evaluation.

Results

Antidepressant use was $39.0 \%$, overall, and was higher in BD II versus BD I (46.9\% versus $30.5 \%, p=0.0002$ ). Both $B D I$ and $B D ~ I I$ antidepressant compared to nonantidepressant users had higher rates of complex pharmacotherapy ( $\geq 4$ mood stabilizers, antipsychotics, and/or antidepressants) and use of other psychotropics. Antidepressant use in BD II versus BD I was higher during euthymia (44.0\% vs. $28.0 \%)$ and subsyndromal symptoms (56.1\% vs. $28.6 \%$ ), but not depression or mood elevation.

Limitations

American tertiary BD clinic referral sample receiving open naturalistic treatment. Conclusions

In our sample, antidepressant use was higher in BD II versus BD I patients, and was associated with markers of heightened illness severity in both BD I and BD II patients. Additional research is warranted to investigate these complex relationships.

Keywords

Bipolar disorderAntidepressant Illness characteristics 


\section{Introduction}

The use of antidepressants in the treatment of bipolar disorder (BD) is a subject of considerable controversy. Data on the efficacy and safety of antidepressants both in acute and long term treatment of BD are commonly variable (Bowden et al., 2012, Sachs et al., 2007, Sidor and Macqueen, 2011, Pacchiarotti et al., 2013). Indeed, an International Society for Bipolar Disorders task force concluded that evidence is lacking to support definitive consensus recommendations on the use of antidepressants in BD, yet cautious antidepressant use may be appropriate for certain BD patients (Pacchiarotti et al., 2013). Nevertheless, despite concerns of mood instability and hypomania/mania associated with antidepressant use (El-Mallakh et al., 2015) and lack of robust efficacy data for treatment of bipolar depression with antidepressants (Sidor and Macqueen, 2011), antidepressants have been the most common medications used in the treatment of BD (Baldessarini et al., 2007). This may be due to unmet pharmacological needs in the treatment of depressive morbidity in BD (Frye et al., 2009, Goldberg, 2012, Kasper et al., 2008) as well as tolerability limitations of the three FDA-approved bipolar depression treatments, all of which have an antipsychotic component (Ketter, 2015, Mclntyre et al., 2013). Research regarding the use of antidepressants in BD has focused more on treatment of bipolar I disorder (BD I) patients (Tohen at al, 2003), leaving questions regarding antidepressant use in bipolar II disorder (BD II) patients (Amsterdam and Brunswick, 2003). The risk of antidepressant associated mood elevation may be lower in BD II versus BD I (Bond et al., 2008, Vohringer et al., 2015); however, the data on effectiveness of antidepressants in BD II are limited and conflicting (Amsterdam et al., 2015, Gijsman et al., 2004, Sidor and Macqueen, 2011). Some data indicate higher rates of treatment-emergent antidepressant switching in BD II versus unipolar major depressive disorder (Peet, 1994) and in BD I versus BDIl (Altshuler et al., 2006; Bond et al., 2008; Vasquez et al., 2011; Vohringer et al., 2015), and that antimanic agents may attenuate this risk (Tondo et al., 2010; Pacchiarotti et al., 2011). Few studies have compared BD I versus BD II patients with respect to clinical correlates of antidepressant use (Undurraga et al., 2012, Lorenzo et al., 2012, Vohringer et al., 2015). Understanding the demographic and illness characteristics associated with antidepressant use in BD I versus BD II patients could improve our understanding of how and when antidepressants are used for treatment of BD in clinical practice.

In this paper, we examined prevalence, and demographic and clinical correlates of antidepressant use in BD I versus BD II patients in a tertiary BD outpatient clinic.

2. Methods

We included outpatients with BD I or BD II referred by community practitioners (primarily psychiatrists) to the Stanford University BD Clinic between 2000 and 2011. Patients were assessed with the Systematic Treatment Enhancement Program for BD (STEP-BD) Affective Disorders Evaluation (Sachs et al., 2003), which included the Structured Clinical Interview for the Diagnostic and Statistical Manual of Mental Disorders, 4th edition (First et al., 1996) mood disorders module and Clinical Global Impression-Bipolar Version-Overall Severity (CGI-BP-OS) score (Spearing et al., 1997). The Mini International

Neuropsychiatric Interview (MINI) (Sheehan et al., 1998) was used to confirm bipolar and comorbid psychiatric disorder diagnosis.

Bipolar disorder subtype (BD II vs. BD I) was determined from available medical records and patient and in most cases significant other report, as assessed by the STEP-BD Affective Disorders Evaluation and MINI. Current mood symptoms were determined from patient report, as assessed by the STEP-BD Affective Disorders Evaluation at the time of enrollment, and clinician observation and reflected any mood symptoms in the 10 days prior to enrollment. Current psychotropic medication use was based upon patient report, as assessed by the STEP-BD Affective Disorders Evaluation, and review of medical 
records at the time of enrollment. Antidepressants included Selective Serotonin Reuptake Inhibitors (SSRIs), Serotonin Norepinephrine Reuptake Inhibitors (SNRIs), Atypical Antidepressants (e.g., bupropion, mirtazapine), and First-Generation Antidepressants (e.g., heterocyclic antidepressants, monoamine oxidase inhibitors).

As described below, demographic and clinical characteristics of participants were evaluated. The STEP-BD protocol and the subsequent similar Stanford-specific Assessment, Monitoring, and Centralized Database protocol were approved by the Stanford University Administrative Panel on Human Subjects, and patients provided verbal and written informed consent prior to participation. Trained medical and research staff collected data on six demographic parameters and 25 illness characteristics/current mood symptoms/current psychotropic medications. The demographic parameters assessed were (A) Age (in years); (B) Gender; (C) Race/Ethnicity; (D) Education; (E) Marital Status; and

(F) Employment status. Illness characteristics/current mood symptoms/current psychotropic medications assessed were (1) lifetime anxiety disorder; (2) lifetime alcohol/substance use disorder; (3) lifetime eating disorder; (4) lifetime personality disorder; (5) bipolar disorder subtype (BD I versus BD II); (5A) lifetime psychosis (which is very commonly associated with $\mathrm{BD} I)$; (5B) lifetime prior psychiatric hospitalization (which is also very commonly associated with $\mathrm{BD} I) ;(6) \geq$ one first-degree relative with mood disorder; (7) onset age (in years); (8) Childhood (age < 13 years) onset; (9) illness duration (in years); (10) long illness duration ( $\geq 15$ years); (11) episode accumulation ( $\geq 10$ prior mood episodes); (12) lifetime suicide attempt; (13) rapid cycling ( $\geq 4$ episodes) in prior year; (14) current CGI-BP-OS; current (i.e., any in the prior 10 days) (15) sadness; (16) anhedonia; (17) euphoria; (18) irritability; and (19) anxiety; and current (baseline) (20) mood stabilizer (MS, lithium, valproate, carbamazepine, and/or lamotrigine) use; (21) antipsychotic (AP) use; (22) antidepressant (AD) use; (23) anxiolytic/hypnotic (AN) use; (24) complex pharmacotherapy ( $\geq 4 \mathrm{MS}, \mathrm{AP}$, or AD); and (25) number of core psychotropics (MS, AP, or AD).

Statistical analyses were performed using Statistical Package for the Social Sciences (SPSS) Version 23.0 software (IBM Corp.; Armonk, NY, USA) on an Apple MacBook Air computer (Apple Corporation, Cupertino, CA, USA). Prevalence and clinical correlates of baseline antidepressant use stratified by bipolar subtype were examined. Analytical statistics included Fisher's Exact test comparisons of categorical data and independentsample $t$-test comparisons of continuous variables. In addition, binary logistic regression was used to adjust for potential confounding variables. Results were presented both with and without Bonferroni adjustment for multiple comparisons, with significance thresholds of $p<0.0007$ (based on 70 comparisons) and $p<0.05$, respectively.

\section{Results}

3.1. Overall demographics and illness characteristics

Table 1 includes demographics, illness characteristics, and current mood symptoms/psychotropic medications of BD patients with and without current antidepressant use stratified by bipolar subtype. Among 503 bipolar disorder outpatients referred to the Stanford University Bipolar Disorder Clinic, 243 (48.3\%) had BD I and 260 $(51.7 \%)$ had BD II. Data were missing for $10.5 \%$ of patients with respect to having had at least 10 prior mood episodes, but only for $0.0-6.0 \%$ for each of the other individual parameters in Table 1. Among all patients, mean \pm SD age was $35.6 \pm 13.1$ years, $58.3 \%$ were female, mean bipolar illness duration was $17.7 \pm 13.1$ years, current mean CGI-BPOS score was $3.9 \pm 1.5$, and current mean number of core psychotropics (MS, AP, AD) was $2.3 \pm 1.6$.

Table 1. Demographics and IIIness Characteristics in BD Patients With Versus Without Antidepressant Use. 
N (\%)

Demographics
A. Age (years, mean \pm SD)
B. Female (\%)
C. Caucasian (\%) (
D. College degree (\%)
E. Married (current, \%)
F. Full time Employment (current, \%)
Comorbid Disorders (lifetime, \%)
1. Anxiety
2. Alcohol/Substance Use
3. Eating
4. Personality
Other Illness Characteristics

5. Bipolar II disorder (\%)

5A. Psychosis (lifetime, \%)

5B. Psychiatric Hospitalization (lifetime, \%)

6. $\geq$ One $1^{\circ}$ Relative w Mood Disorder (\%)

7. Onset age (years, mean \pm SD)

8. Childhood (age $<13$ years) Onset (\%)

9. IIIness Duration (years, mean \pm SD)

10. Long Illness Duration ( $\geq 15$ years, \%)

11. Episode accumulation ( $\geq 10$, lifetime, $\%$ )

12. Suicide Attempt (lifetime, \%)

13. Rapid Cycling ( $\geq 4$ episodes in prior year, \%)

14. CGI-BP-OS (current, mean \pm SD)

Mood Symptoms (any in prior 10 days, \%)

15. Sadness
16. Anhedonia
17. Euphoria
18. Irritability
19. Anxiety

Medication Use (current)

20. Mood Stabilizer (MS, \%)

21. Antipsychotic (AP, \%)

22. Antidepressant (AD, \%)

23. Anxiolytic/Hypnotic (AN, \%)

25. Complex Pharmacotherapy ( $\geq 4$ MS, AP, AD, \%)

26. Number of Core Psychotropics (MS, AP, AD, mean \pm SD) w/ AD

$74(30.5)^{* * *} 169(69.5) \quad 122(4$

$35.1 \pm 12.8$

$35.0 \pm$

13.4

59.5

$85.1^{*}$

32.4

36.5

32.4

63.5

85.1

23.0*

9.5

0.0

64.9

63.5

$66.2^{\text {** }}$

$18.4 \pm 8.2$

21.6

$16.8 \pm 12.8$

51.5

71.6

30.0

33.1

25.4

$38.4 \pm$

68.0

85.2

23.0*

40.2

32.0

76.2

75.4

18.0

16.4

100.0

13.1

11.5

62.3

$17.1 \pm$

32.8

$21.1 \pm$

43.1

58.2

$47.3^{\star \star \star}$

18.9

$4.0 \pm 1.5^{\star}$

29.7

$44.6^{\text {** }}$

21.6

28.4

59.5

46.2

$19.1 \pm 8.1$

20.7

$15.9 \pm$

13.1

36.4

47.8

24.9

10.1

$61.2^{*}$

80.7

31.2

27.0

$3.5 \pm 1.6$

$4.0 \pm$

33.6

19.5

$42.6^{*}$

16.4

40.2

72.1

83.7

24.8

21.9

40.2

53.8

68.9*

54.1

89.3

51.5

0.0

27.0

100.0

5.9

9.5

21.9

100.0

10.7

50.0

$2.3 \pm 1.4$

CGI-BP-OS indicates Clinical Global Impression for Bipolar Disorder-Overall Severity; SD indicates standard deviation; w indicates with; wo indicates without.

Boldface font indicates parameters with statistically significant relationships with antidepressant use.

Missing data: $10.5 \%$ for $\geq 10$ prior episodes, $0.0-6.0 \%$ for other parameters.

$$
\begin{aligned}
& p<0.05 \\
& p<0.01
\end{aligned}
$$


$\mathrm{p}<0.001$.

$* \star * *$

$p<0.0001$ for those taking versus not taking antidepressants.

3.2. Prevalence and demographic and clinical characteristics of patients with current antidepressant use, stratified by bipolar subtype

A description of overall prevalence and demographics and illness characteristics of BD patients in the sample taking and not taking at least one antidepressant, stratified by bipolar subtype, is shown in Table 1. The overall rate of current antidepressant use was $196 / 503$ (39.0\%). 137 patients (27.2\% of all patients, $69.9 \%$ of patients with current antidepressant use) took antidepressants in combination with at least one antimanic agent (i.e. lithium, valproate, carbamazepine, and/or antipsychotic).

Among BD I patients, baseline antidepressant users compared to nonusers were fewer (30.5\% vs. $69.5 \%$, Chi-square $=74.3, \mathrm{df}=1, \mathrm{p}<0.0001)$; whereas in BD II patients, there was no significant difference between percentages of (baseline antidepressant users and nonusers (46.9\% vs. $53.1 \%)$ ). Indeed, BD II patients compared to BD I patients were significantly more often taking baseline antidepressant $(46.9 \%$ vs. $30.5 \%$, Chi-square $=14.3, \mathrm{df}=1, \mathrm{p}=0.0002$ ) (Fig. 1). In contrast BD I compared to BD II patients were significantly more often taking baseline antipsychotics $(50.0 \%$ versus $28.3 \%$, Chi-square $=25.9$, df $=1, p<0.0001)$, mood stabilizers $(76.1 \%$ versus $59.6 \%$, Chi-square $=15.6$, df $=1, p<0.0001)$, and valproate $(35.9 \%$ versus $11.3 \%$, Chi-square $=43.0, \mathrm{df}=1$, $p<0.0001)$ (not illustrated). All of these findings retained statistical significance after adjusting for multiple comparisons.

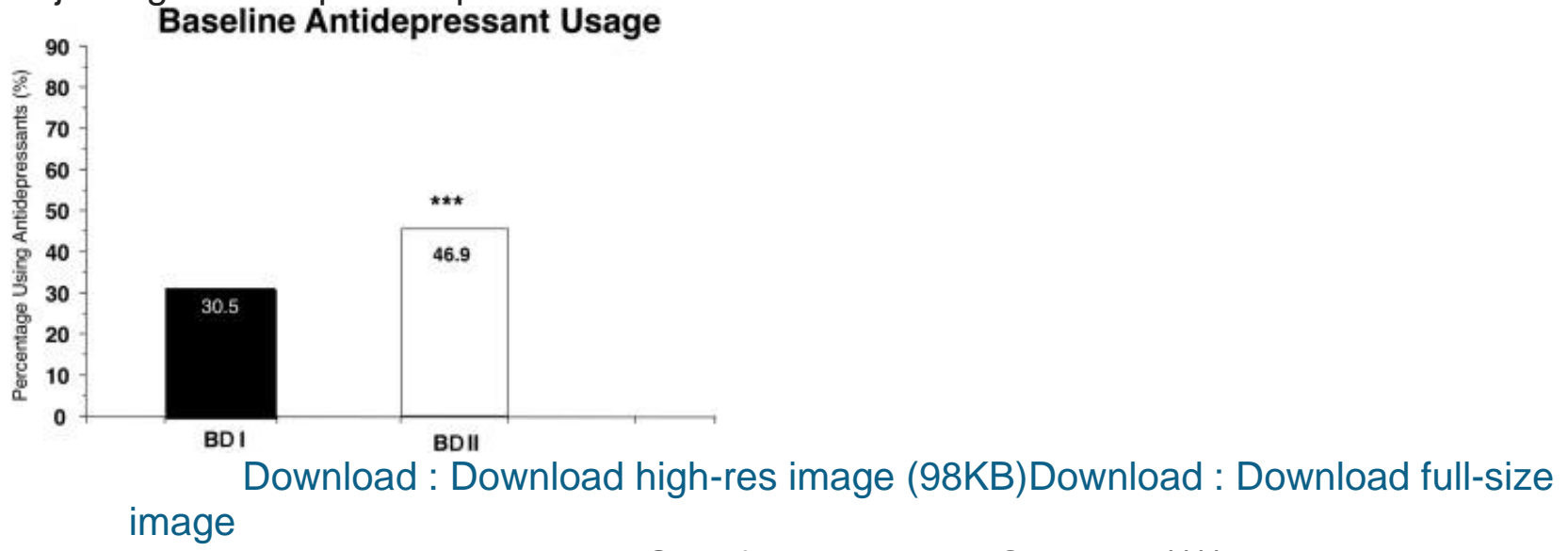

Fig. 1. Baseline Antidepressant Use Stratified by Bipolar Subtype. ${ }^{* * *} p=0.0002$ versus BD I. BD I indicates bipolar I disorder; BD II indicates bipolar II disorder.

Regarding socio-demographics, BD I (but not BD II) antidepressant users $(\mathrm{N}=74)$ versus nonusers $(\mathrm{N}=169)$ were more often Caucasian $(85.1 \%$ vs. $71.6 \%$, Chi-square $=5.1$, df $=1$, $p=0.02)$, whereas BD II (but not BD I) antidepressant users $(N=122)$ versus nonusers $(N$ $=138)$ were older $(38.4 \pm 13.2$ vs. $34.0 \pm 13.4, t=2.6, d f=258, p=0.009)$ and less likely to have had a college degree $(23.0 \%$ vs. $35.5 \%$, Chi-square $=4.9, \mathrm{df}=1, \mathrm{p}=0.03)$. None of these socio-demographic differences retained significance after adjusting for multiple comparisons.

As for illness characteristics, BD I (but not BD II) antidepressant users versus non-users more often had lifetime eating disorder $(23.0 \%$ vs. $10.1 \%$, Chi-square $=7.1$, df $=1$, $p=0.01)$, at least one first-degree relative with mood disorder $(66.2 \%$ vs. $46.2 \%$, Chisquare $=8.3, \mathrm{df}=1, \mathrm{p}=0.005)$, and prior suicide attempt $(47.3 \%$ vs. $24.9 \%$, Chi-square $=12.0, \mathrm{df}=1, \mathrm{p}=0.0009)$ and had higher CGI-BP-OS scores (4.0 \pm 1.5 vs. $3.5 \pm 1.6$, $\mathrm{t}=2.3$, df $=241, \mathrm{p}=0.02$ ). BD II (but not BD I) antidepressant users versus non-users had longer illness duration ( $21.1 \pm 13.5$ vs. $17.3 \pm 12.4, t=2.3, d f=258, p=0.02)$ and were 
more likely to have long illness duration (more than 15 years) $(61.2 \%$ vs. $48.5 \%$, Chisquare $=4.1, \mathrm{df}=1, \mathrm{p}=0.045)$. Among both $\mathrm{BD} I$ and $\mathrm{BD}$ II antidepressant users versus non-users, there were higher rates of current anhedonia ( $44.6 \%$ vs. $24.8 \%$, Chi-square $=9.4$, df $=1, p=0.003$; and $42.6 \%$ vs. $28.1 \%$, Chi-square $=5.9$, df $=1, p=0.02$, respectively). BD II (but not $B D I$ ) antidepressant users versus non-users also had a lower rate of current irritability $(40.2 \%$ vs. $59.4 \%$, Chi- square $=9.6, d f=1, p=0.003)$. With respect to current psychotropic use, BD II (but not BD I) antidepressant users versus nonusers were more often taking a mood stabilizer ( $68.9 \%$ vs. $53.6 \%$, Chi-square $=6.3$, df $=1, p=0.02$ ), whereas both $\mathrm{BD} I$ and $\mathrm{BD} \mid \mathrm{I}$ antidepressant users versus nonusers were more often taking complex pharmacotherapy (Goldberg et al., 2009) $(50.0 \%$ vs. $21.9 \%$ in BDI, Chi-square $=19.2, \mathrm{df}=1, \mathrm{p}<0.0001$; and $45.1 \%$ vs. $17.4 \%$ in BD II, Chi-square $=19.2 \mathrm{df}=1, \mathrm{p}<0.0001$, respectively) and were taking more core psychotopics (MS, $A D$, AP) $(3.7 \pm 1.6$ vs. $2.3 \pm 1.4, t=6.9, \mathrm{df}=241, \mathrm{p}<0.0001$ in $\mathrm{BDI}$; and $3.5 \pm 1.6$ vs. $1.7 \pm 1.7$, $\mathrm{t}=8.8 \mathrm{df}=258, \mathrm{p}<0.0001$ in BDII). After adjusting for multiple comparisons with respect to illness characteristics, only the findings that $\mathrm{BD} I$ and $\mathrm{BD}$ II antidepressant users versus nonusers were more often taking complex pharmacotherapy, and were taking more core psychotropics, retained statistical significance.

3.3. Current antidepressant use in BD I versus BD II stratified by mood state In our sample of 503 bipolar patients at enrollment, 207 (41.2\%) patients were euthymic (107 BD I and 100 BD II), 153 (30.4\%) were depressed (59 BD I and 94 BD II), 76 (15.1\%) had subsyndromal symptoms (35 BD I and $41 \mathrm{BD}$ II), and 54 (10.7\%) met criteria for mood elevation (33 BD I and 21 BD II).

Fig. 2 depicts antidepressant usage in BD II versus BD I, stratified by current mood state. Antidepressant use in BD II versus BD I was significantly higher in euthymic patients and patients with subsyndromal symptoms $(44.0 \%$ vs. $28.0 \%$, Chi-square $=5.7, \mathrm{df}=1$, $p=0.02$; and $56.1 \%$ vs. $28.6 \%$, Chi-square $=5.8, d f=1, p=0.02$ ), though these findings were no longer significant after adjusting for multiple comparisons. Antidepressant use in BDII versus BDI did not significantly differ during depression (49.0\% vs. $37.3 \%)$ or mood elevation (28.6\% vs. $30.3 \%$, Fig. 2). Current antidepressant use in BDII was only nonsignificantly lower when elevated (28.6\%) compared to when euthymic $(44.0 \%)$, depressed $(49.0 \%)$, or with subsyndromal symptoms $(56.1 \%)$. Finally, current antidepressant use in BD I was only non-significantly higher when depressed (37.3\%) compared to when euthymic $(28.0 \%)$, with subsyndromal symptoms $(28.6 \%)$, or elevated $(30.3 \%)$.

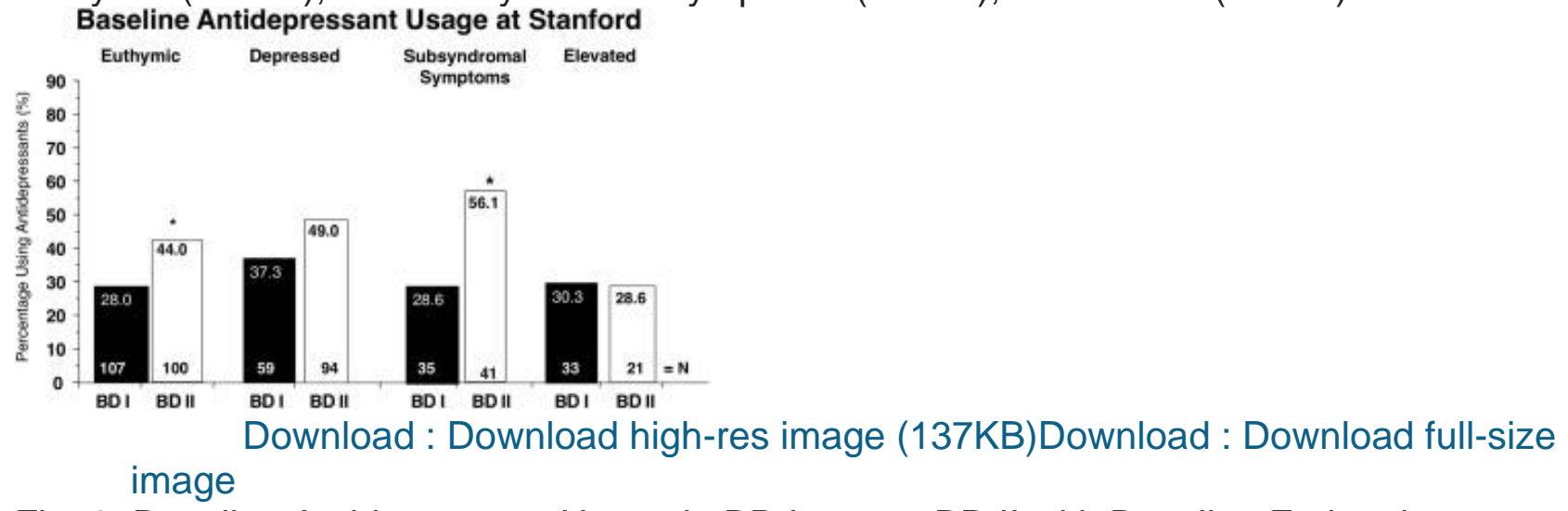

Fig. 2. Baseline Antidepressant Usage in BD I versus BD II with Baseline Euthymia, Depression, Subsyndromal Symptoms, and Mood Elevation. * $p<0.05$ versus BD I. BD I indicates bipolar I disorder; BD II indicates bipolar II disorder.

4. Discussion

Antidepressant use in the treatment of BD remains controversial. Some randomized, controlled studies have suggested that antidepressants may yield benefit for acute bipolar depression, either as monotherapy in bipolar II disorder (Amsterdam and Shults, 2010) or 
added to an antipsychotic in bipolar I disorder (Tohen et al., 2003). Another study that was randomized, but not placebo-controlled, suggested similar efficacy of antidepressant and lithium monotherapy for longer-term relapse prevention in bipolar II disorder patients (Amsterdam et al., 2015). Overall, however, there are few adequately powered, randomized, controlled studies investigating the efficacy of antidepressants for the treatment of BD, and many of these failed to demonstrate superiority of antidepressants over placebo (Pacchiarotti et al., 2013). Despite the limited evidence base to support their utility, antidepressants are commonly prescribed for BD patients (Baldessarini et al., 2007), thus warranting an examination of clinical factors associated with antidepressant use in BD patients and how such factors may differ across bipolar subtypes.

The overall use of antidepressants in our sample was $39.0 \%$. Rates of antidepressant use in prior studies range between $30 \%$ and $80 \%$ (Baldessarini et al., 2007, Carta et al., 2012, Ghaemi et al., 2000, Lorenzo et al., 2012). The higher prevalence of antidepressant use in earlier studies could reflect prior under diagnosis of BD (Ghaemi et al., 2000) and the lack of separate FDA-approvals for bipolar versus unipolar depression prior to 2003 (Tohen et al., 2003), while the lower prevalence of antidepressant use in our study was more consistent with other studies (Baldessarini et al., 2007, Carta et al., 2012) and may be related to the relative reluctance of community based providers practicing near an academic tertiary center to prescribe antidepressants for BD patients.

Several of our findings on clinical variables, particularly with respect to increased rate of complex pharmacotherapy and increased number of core psychotropics associated with antidepressant use, are consistent with overall higher severity of illness in BD patients taking versus not taking antidepressants. The heightened severity associated with antidepressants may reflect greater utilization of antidepressants during depressed mood states, (Ketter, 2015, Mclntyre et al., 2013, Pacchiarotti et al., 2013) and greater illness burden associated with depression rather than mood elevation (Miller et al., 2014). Indeed, BD patients appear to experience depressive symptoms three times more often than they do manic or hypomanic symptoms (Judd et al., 2002); and can take twice as long to recover from depression compared to mania, (Hlastala et al., 1997), often necessitating use of agents such as antidepressants despite their lack of robust efficacy data in BD (Pacchiarotti et al., 2013).

Our results show that BD II patients referred to our clinic were more often taking antidepressants compared to BD I patients. This might be due to lower clinician concern for degree of severity or risk of treatment-emergent antidepressant associated mood elevation in BD II compared to BD I, as shown in prior studies (Bond et al., 2008, Vieta et al., 2002; Altshuler et al., 2006). Increased use of antidepressants in BD II is further supported by research demonstrating that antidepressants may have similar prophylactic effectiveness compared to mood stabilizers in preventing depressive relapses in BD II (Amsterdam et al., 2015). Moreover, our data are consistent with previous research suggesting antidepressants should be used more cautiously in BD I due to concerns of the risk of serious mood elevation (Vohringer et al., 2015, Vieta et al., 2002, Altshuler et al., 2006).

We also showed that antidepressant use tended to be higher in BD II vs BD I patients during euthymic and subsyndromal mood states, but was not significantly different when patients were depressed or elevated. This finding could be related to increased use of antidepressants during depression in BD I patients and decreased use of antidepressants during mood elevation in BD II patients (Fig. 2).

Our study has the strengths of assessing demographics and illness characteristics in a substantial sample of well-characterized BD I and BD II patients taking antidepressants referred to a tertiary academic clinic. However, these strengths are accompanied by limitations that include the use of a sample referred to a suburban Northern California BD 
specialty clinic, limiting the generalizability of our findings in our relatively affluent and welleducated but underemployed, predominantly female sample of BD patients with medical insurance, rather than a more heterogeneous mixture of BD inpatients and outpatients being treated in non-specialty clinical settings. Another limitation is the open naturalistic cross-sectional (rather than longitudinal) treatment design, in which patients received diverse uncontrolled therapies. Also, we were not able to determine causality regarding associations between baseline antidepressant use and clinical correlates (e.g., whether antidepressant administration increased rate of current anhedonia or vice versa), nor were we able to determine potentially heterogeneous reasons for antidepressant administration (e.g., for anxiety versus depression).

5. Conclusion

Given the commonly inadequate outcomes associated with bipolar depression and antidepressant use, further examination of this relationship is warranted in order to better understand mechanisms and clinical implications.

Acknowledgement

This research was supported by a Government of South Korea Overseas Research Fellowship (Dr. Park, 2014-I-0040), 2014 and 2015 Research Year Grants from Inje University (Dr. Hyun Kim), the Pearlstein Family Foundation, the Mitchell Foundation, and the Holland Foundation. These data have been submitted for presentation at the 170th Annual Meeting of the American Psychiatric Association in New York, New York, May 0509, 2018.

Disclosure of financial relationships (past 36 months)

Drs. Hooshmand, Gershon, Park, Kim, and Wang as well as Dennis Do, Saloni Shah, and Laura Yuen report no financial relationships with commercial interests. Dr. Miller has received grant/research support from Merck and Company and Sunovion, Inc. Dr. Dell'Osso has received grant/research support from Cyberonics, Inc. and AstraZeneca and Lundbeck and Lecture Honoraria from AstraZeneca and Lundbeck. Dr. Ketter has received grant/research support from the Agency for Healthcare Research and Quality, AstraZeneca Pharmaceuticals LP, Cephalon Inc., Eli Lilly and Company, National Institute of Mental Health, Pfizer Inc., and Sunovion Pharmaceuticals; Consultant Fees from Allergan, Inc., Avanir Pharmaceuticals, Bristol-Myers Squibb Company, Cephalon Inc., Forest Pharmaceuticals, Janssen Pharmaceutical Products, LP, Merck \& Co., Inc., Sunovion Pharmaceuticals, and Teva Pharmaceuticals; Lecture Honoraria from Abbott Laboratories, Inc., AstraZeneca Pharmaceuticals LP, GlaxoSmithKline, and Otsuka Pharmaceuticals; and Publication Royalties from American Psychiatric Publishing, Inc. In addition, Dr. Ketter's spouse was an employee of and holds stock in Janssen Pharmaceuticals.

Authors statement

All authors have seen and approved the final version of the manuscript being submitted to Journal of Affective Disorders, titled "Differential Prevalence and Demographic and Clinical Correlates of Antidepressant Use in American Bipolar I versus Bipolar II Disorder Patients." The authors certify that the submitted manuscript represents their original work, has not received prior publication, and is not under consideration for publication elsewhere.

Role of the funding source

This research was supported by a Government of South Korea Overseas Research Fellowship (Dr. Park, 2014-I-0040), 2014 and 2015 Research Year Grants from Inje University (Dr. Hyun Kim), the Pearlstein Family Foundation, the Mitchell Foundation, and the Holland Foundation. The funding sources had no role in the study's design, the collection, analysis and interpretation of data, the writing of the report, or in the decision to submit the article for publication. 


\section{References}

Altshuler et al., 2006

L.L. Altshuler, T. Suppes, D.O. Black, W.A. Nolen, G. Leverich, P.E. Keck Jr, M.A. Frye, R. Kupka, S.L. McElory, H. Grunze, C.M.R. Kitchen

Post R: lower switch rate in depressed patients with bipolar II disorder than bipolar I disorder treated adjunctively with second-generation antidepressants

Am. J. Psychiatry, 163 (2006), pp. 313-315

CrossRefGoogle Scholar

Amsterdam et al., 2015

J.D. Amsterdam, L. Lorenzo-Luaces, I. soeller, S.Q. Li, J.J. Mao, R.J. DeRubeis

Safety and effectiveness of continuation antidepressant versus mood stabilizer monotherapy for relapse-prevention of bipolar II depression: a randomized, doubleblind, parallel-group, prospective study

J. Affect. Disord., 185 (2015), pp. 31-37

ArticleDownload PDFView Record in ScopusGoogle Scholar

Amsterdam and Shults, 2010

J.D. Amsterdam, J. Shults

Efficacy and safety of long-term fluoxetine versus lithium monotherapy of bipolar II disorder: a randomized, double-blind, placebo-substitution study

AJP, 167 (2010), pp. 792-800

CrossRefView Record in ScopusGoogle Scholar

Amsterdam and Brunswick, 2003

J.D. Amsterdam, D.J. Brunswick

Antidepressant monotherapy for bipolar type II major depression

Bipolar Disord., 5 (2003), pp. 388-395

View Record in ScopusGoogle Scholar

Baldessarini et al., 2007

R.J. Baldessarini, L. Leahy, S. Arcona, D. Gause, W. Zhang, J. Hennen

Patterns ofpsychotropic drug prescription for U.S patients with diagnosis of bipolar disorders

Psychiatr. Serv., 58 (2007), pp. 85-91

View Record in ScopusGoogle Scholar

Bond et al., 2008

D.J. Bond, M. Noronha, M. Kauer-Sant'Anna, R.W. Lam, L.N. Yatham, et al.

Antidepressant-associated mood elevations in bipolar II disorder compared with bipolar I disorder and major depressive disorder: a systematic review and metaanalysis

J. Clin. Psychiatry, 69 (2008), pp. 1589-1601

CrossRefView Record in ScopusGoogle Scholar

Bowden et al., 2012

C.L. Bowden, R.H. Perlis, M.E. Tahse, T.A. Ketter, M.M. Ostacher, J.R. Calabrese, N.A.

Reilly-Harrington, J.M. Gonzalez, V. Singh, A.A. Nierenberg, G.S. Sachs

Aims and results of the NIMH Systematic Treatment Enhancement Program for

Bipolar Disorder (STEP-BD)

CNS Neurosci. Ther., 18 (2012), pp. 243-249

CrossRefView Record in ScopusGoogle Scholar

Carta et al., 2012

M.G. Carta, E. Aguglia, M. Balestrieri, J.R. Calabrese, F. Caraci, L. Dell'Osso, G. Di

Sciascio, F. Drago, C. Faravelli, M.E. Lecca, M.F. Moro, M. Nardini, G. Palumbo, M.C. Hardoy 
The lifetime prevalence of bipolar disorders and the use of antidepressant drugs in bipolar depression in Italy

J. Affect. Disord., 136 (3) (2012), pp. 775-780

ArticleDownload PDFView Record in ScopusGoogle Scholar

El-Mallakh et al., 2015

R.S. El-Mallakh, P.A. Vöhringer, M.M. Ostacher, C.F. Baldassano, N.S. Holtzman, E.A.

Whitham, S.B. Thommi, F.K. Goodwin, S.N. Ghaemi

Antidepressants worsen rapid-cycling course in bipolar depression: A STEP-BD randomized clinical trial

J Affect. Disord., 184 (2015), pp. 318-321

ArticleDownload PDFView Record in ScopusGoogle Scholar

First et al., 1996

M.B. First, R.L. Spitzer, M. Gibbon, J.B.W. Williams

Structured Clinical Interview for DSM-IV Axis I Disorders, Patient Edition (SCID-I/P, Version 2.0)

New York: Biometrics Research Department, New York State Psychiatric Institute, New York (1996)

Google Scholar

Frye et al., 2009

M.A. Frye, G. Helleman, S.L. McElroy, L.L. Altshuler, D.O. Black, P.E. Keck Jr., et al.

Correlates of treatment-emergent mania associated with antidepressant treatment in bipolar depression

Am. J. Psychiatry, 166 (2009), pp. 164-172

CrossRefView Record in ScopusGoogle Scholar

Ghaemi et al., 2000

S.N. Ghaemi, E.E. Boiman, F.K. Goodwin

Diagnosing bipolar disorder and the effect of antidepressants: a naturalistic study

J. Clin. Psychiatry, 61 (2000), pp. 804-808

CrossRefView Record in ScopusGoogle Scholar

Gijsman et al., 2004

H.J. Gijsman, J.R. Geddes, J.M. Rendell, et al.

Antidepressants for bipolar depression: a systematic review of randomized, controlled trials

Am. J. Psychiatry, 161 (2004), pp. 1537-1547

View Record in ScopusGoogle Scholar

Goldberg, 2012

J.F. Goldberg

Antidepressants: the scapegoat of poor outcome bipolar disorder?

Aust. N. Z. J. Psychiatry, 46 (2012), pp. 302-305

CrossRefView Record in ScopusGoogle Scholar

Hlastala et al., 1997

S.A. Hlastala, E. Frank, A.G. Mallinger, M.E. Thase, A.M. Ritenour, D.J. Kupfer

Bipolar depression: an underestimated treatment challenge

Depress. Anxiety, 5 (1997), pp. 73-83

View Record in ScopusGoogle Scholar

Judd et al., 2002

L.L. Judd, H.S. Akiska, P.J. Shcettler, J. Endicott, J. Maser, D.A. Solomon, A.C. Leon, J.A.

Rice, M.B. Keller

The long-term natural history of weekly symptomatic status of bipolar I disorder Arch. Gen. Psychiatry, 59 (2002), pp. 530-537

View Record in ScopusGoogle Scholar 
Kasper et al., 2008

S. Kasper, J.R. Calabrese, G. Johnson, O. Tajima, E. Vieta, A. Viguera, et al. International consensus Group on the evidence-based pharmacologic treatment of bipolar I and II depression

J. Clin. Psychiatry, 69 (2008), pp. 1632-1646

View Record in ScopusGoogle Scholar

Ketter, 2015

T.A. Ketter

Advances in the Treatment of Bipolar Disorder

American Psychiatric Publishing Inc, Washington, DC (2015)

Google Scholar

Lorenzo et al., 2012

L.S. Lorenzo, G.H. Vasquez, R.M. Zarattegui, L. Tondo, R. Baldassarini

Characteristics of bipolar disorder patients given antidepressants

Hum. Psychopharmacol. Clin. Exp., 27 (2012), pp. 486-491

CrossRefView Record in ScopusGoogle Scholar

Miller et al., 2014

S. Miller, B. Dell'Osso, T.A. Ketter

The prevalence of burden of bipolar depression

J. Affect. Disord., 169 (Suppl. 1) (2014), pp. S3-S11

ArticleDownload PDFView Record in ScopusGoogle Scholar

Mclntyre et al., 2013

R.S. McIntyre, D.S. Cha, R.D. Kim, R.B. Mansur

A review of FDA-approved treatment options in bipolar depression

CNS Spectr., 18 (Suppl. 1) (2013), pp. 4-20

Google Scholar

Pacchiarotti et al., 2011

I. Pacchiarotti, M. Valenti, F. Colom, A.R. Rosa, A.M. Nivoli, A. Murru, J. Sanchez-Moreno,

E. Vieta

Differential outcome of bipolar patients receiving antidepressant monotherapy versus combination with an anti-manic drug

J. Affect. Disord., 129 (1-2) (2011), pp. 321-326

ArticleDownload PDFView Record in ScopusGoogle Scholar

Pacchiarotti et al., 2013

I. Pacchiarotti, D.J. Bond, R.J. Baldessarini, W.A. Nolen, H. Grunze, R.W. Licht, et al.

The International Society for bipolar disorders (ISBD) task force report on antidepressant use in bipolar disorders

Am. J. Psychiatry, 170 (2013), pp. 1249-1262

CrossRefView Record in ScopusGoogle Scholar

Peet, 1994

M. Peet

Induction of mania with selective serotonin re-uptake inhibitors and tricyclic antidepressants

Br. J. Psychiatry, 164 (1994), pp. 549-550

CrossRefView Record in ScopusGoogle Scholar

Sachs et al., 2007

G.S. Sachs, A.A. Nierenberg, J.R. Calabrese, et al.

Effectiveness of adjunctive antidepressant treatment for bipolar depression

N. Engl. J. Med., 356 (17) (2007), pp. 1711-1722

View Record in ScopusGoogle Scholar

Sachs et al., 2003 
G.S. Sachs, M.E. Thase, M.W. Otto, M. Bauer, D. Miklowitz, S.R. Wisniewski, P. Lavori, B. Lebowitz, M. Rudorfer, E. Frank, A.A. Nierenberg, M. Fava, C. Bowden, T. Ketter, L.

Marangell, J. Calabrese, D. Kupfer, J.F. Rosenbaum

Rationale, design, and methods of the systematic treatment enhancement program for bipolar disorder (STEP-BD)

Biol. Psychiatry, 53 (2003), pp. 1028-1042

ArticleDownload PDFView Record in ScopusGoogle Scholar

Sheehan et al., 1998

D.V. Sheehan, Y. Lecrubier, K.H. Sheehan, P. Amorim, J. Janavs, E. Weiller, et al.

The Mini-International neuropsychiatric Interview (M.I.N.I.): the development and validation of a structured diagnostic psychiatric interview for DSM-IV and ICD- 10

J. Clin. Psychiatry, 59 (1998), pp. 22-33

View Record in ScopusGoogle Scholar

Sidor and Macqueen, 2011

M.M. Sidor, G.M. Macqueen

Antidepressants for the acute treatment of bipolar depression: a systematic review and meta-analysis

J. Clin. Psychiatry, 72 (2) (2011), pp. 156-167

CrossRefView Record in ScopusGoogle Scholar

Spearing et al., 1997

M.K. Spearing, R.M. Post, G.S. Leverich, D. Brandt, W. Nolen

Modification of the Clinical Global Impressions (CGI) Scale for use in bipolar illness (BP): the CGI- BP

Psychiatry Res., 73 (1997), pp. 159-171

ArticleDownload PDFView Record in ScopusGoogle Scholar

Tohen et al., 2003

M. Tohen, E. Vieta, J. Calabrese, T.A. Ketter, G. Sachs, C. Bowden, P.B. Mitchell, F.

Centorrino, R. Risser, R.W. Baker, A.R. Evans, K. Beymer, S. Dube, G.D. Tollefson, A.

Brier

Efficacy of olanzapine and olanzapine-fluoxetine combination in the treatment of bipolar I depression

Arch. Gen. Psychiatry, 60 (11) (2003), pp. 1079-1088

View Record in ScopusGoogle Scholar

Tondo et al., 2010

L. Tondo, G. Vazquez, R.J. Baldessarini

Mania associated with antidepressant treatment: comprehensive meta-analysis review

Acta Psychiatr. Scand., 121 (2010), pp. 404-414

View Record in ScopusGoogle Scholar

Undurraga et al., 2012

J. Undurraga, R.J. Baldessarini, M. Valenti, I. Pacchiarotti, L. Tondo, G. Vazquez, E. Vieta Bipolar depression: clinical correlates of receiving antidepressants

J. Affect. Disord., 139 (1) (2012), pp. 89-93

ArticleDownload PDFView Record in ScopusGoogle Scholar

Vasquez et al., 2011

G. Vasquez, L. Tondo, R.J. Baldessarini

Comparison of antidepressant responses in patient with bipolar vs. unipolar

depression: s meta-analytic review

Pharmacopsychiatry, 44 (2011), pp. 21-26

Google Scholar

Vieta et al., 2002 
E. Vieta, A. Martinez-Arán, J.M. Goikolea, C. Torrent, F. Colom, A. Benabarre, M. Reinares

A randomized trial comparing paroxetine and venlafaxine in treatment of bipolar depressed patients taking mood stabilizers

J. Clin. Psychiatry, 63 (6) (2002), pp. 508-512

CrossRefView Record in ScopusGoogle Scholar

Vohringer et al., 2015

P.A. Vohringer, M.J. Ostacher, R.S. El-Mallakh, N.S. Holtzman, S.B. Thommi, E.A.

Whithman, M.C. Sullivan, C.F. Baldassano, F.K. Goodwin, R.J. Baldessarini, N.S. Ghaemi Antidepressants in type II versus type I bipolar depression. A randomized discontinuation trial

J. Clin. Psychopharmacol., 35 (2015), pp. 605-608

View Record in ScopusGoogle Scholar 